\title{
Reflective Practice through Reflecting Writing: A Case Involving Mathematics and Science Teachers
}

\author{
Dr Abraham Motlhabane \\ College of Education, University of South Africa \\ mot/hat@unisa.ac.za
}

Doi:10.5901/mjss.2013.v4n14p263

\begin{abstract}
What teachers do in the classroom matters deeply. This article reflects on the classroom practices of mathematics and science teachers. Reflection on teacher's experiences in the classroom was seen as vital in improving classroom practice. To unpack teacher's classroom practices, these teachers were asked what they did in the classroom to ensure effective learning and teaching; what areas of the teaching of mathematics and science could be improved to ensure effective teaching and learning; and how teachers could teach better going forward. Data was collected from written responses and focus group interviews with teachers. Common themes were derived from the written responses and transcribed interviews. Motivation was identified as being key to achieving effective learning and teaching.
\end{abstract}

Keywords: Reflective practice, motivation, classroom, learning, teaching, mathematics, science

\section{Introduction}

John Dewey described reflection as "a kind of thinking that consists in turning a subject over in the mind and giving it serious thought"; it is "active, persistent and careful consideration of any belief or supposed form of knowledge in the light of the grounds that support it, and further conclusions to which it leads...it includes a conscious and voluntary effort to establish belief upon a firm basis of evidence and rationality" (Dewey, 1933).

The study reported on here is located within reflective practice. Although the term reflective practice is interpreted and understood in a number of different ways, in this context it is viewed as a means by which teachers are able to develop a greater level of self-awareness about the nature and impact of their classroom practice. It is interpreted in this way in the hope of creating opportunities for professional growth and development (Osterman \& Kottkamp, 1993). Reflective practice is located within both the older tradition of experiential learning and the more recently articulated perspective of situated cognition. Experiential learning theorists, including Dewey, Lewin, and Piaget, maintain that learning is most effective, most likely to lead to behavioural change, when it begins with experience, and specifically problematic experience. From experience and research we know that learning is most effective when people become personally engaged in the learning process, and engagement is most likely to take place when there is a need to learn (Osterman \& Kottkamp, 1993).

These authors further remark that although experience is the basis for learning, learning cannot take place without reflection; moreover, as reflection is essential to the process, reflection cannot be separated from action. Teachers' reflective practice integrates theory and practice, thought and action - a process which could be described as a dialogue of thinking and doing, through which teachers become more skilful (Osterman \& Kottkamp, 1993).

Teachers' reflection involves observation, discovery, and collaborative inquiry and discourse through shared experience. For that reason, classroom experience is seen as both a resource and a stimulus for learning. Through the associated processes of observation and analysis, teachers come to see clearly the discrepancies, incongruities, and failures to reach intentions. The problem begins to emerge more clearly, and teachers begin to see their own role in the problem with greater clarity (Osterman \& Kottkamp, 1993).

In the reflective practice model, the link between theory and practice is explicit rather than implicit, as it is in the traditional approach, and the developmental process begins with practice. The belief on which the study being reported on is founded is that to develop new and better methods of practice, we should begin by examining the classroom practices we want to improve. The central knowledge questions are thus much broader than in the traditional approach: "What do teachers do, and why do they do it?"; "How do their knowledge, understanding and personal theoretical framework affect their classroom practice?"; "Given new knowledge, what will they do differently?" The reflective 
approach integrates several kinds of knowledge: both theory and practice are integral and central considerations, and theory includes ideas derived from both formal research and personal experience. Attention to public knowledge and formal theory is not lost or diminished, but practice - specifically, personal practice- assumes a far greater importance (Osterman \& Kottkamp, 1993).

Teachers' reflective writing therefore involved analysing, reconsidering and questioning experiences within their own environmental context and teaching and learning theories. For example, teachers have found that the realities of their practicum experiences do not match what they may have learnt from theories about teaching and learning. Accordingly, the process of reflecting on the disparities between expectations and actual experience enables teachers to become more closely engaged with the process of their own learning (Moon, 1999). It is through reflection and analysis that the study strives to understand the teachers' experience. Furthermore, examining experience by considering both the teachers' actions and classroom outcomes becomes a means to articulate and understand espoused theories and theories-in-use. Why did events take place as they did? What ideas or feelings prompted teachers' practices? Did their practice correspond with their intentions? Did their practice lead to the outcomes as intended? (Osterman \& Kottkamp, 1993).

To encourage teachers to be reflective is to encourage the development of a habit of processing cognitive material that can lead to ideas that are beyond the curriculum, beyond learning defined by learning outcomes, and beyond those of the teacher who is managing the learning. However, the context in which reflection takes place cannot be overlooked (Boud \& Walker 1998). Hence the analysis of the teachers' written reflections took cognisance of their context.

It is through practice in reflection that we learn to adopt a conscious orientation toward finding the problems. Even though this step may seem difficult or feel "unnatural," the skill develops quickly, because the learning cycle begins with problematic experience. One of the initial tasks of the facilitator in a formal reflective practice setting is to enable individuals to uncover or discover problematic situations within the context of their practice (Osterman \& Kottkamp, 1993).

Teachers found it difficult to identify problems. This is because people generally, and teachers in particular, want to view things positively and to be optimistic. In response to organisational problems, discussion quickly turns to solutions, while problem identification and analysis are cut short Bolman \& Deal, 1991). Identification of personal problems is even more difficult.

An assumption of the study was that finding the problem would motivate the teachers. Because reflective practice focuses on personal behaviour within the professional context, the study began by gathering and analysing rich information about the experience, and particularly about the teachers' experiences (Osterman \& Kottkamp, 1993).

Reflection on the teachers' experience was harnessed because it is viewed as potentially transformative of everyone involved in the teaching and learning of mathematics and science. The approach adopted in the study entailed reflective writing because it is simple and direct. The personal pronouns I and we can be used because participants are reflecting on their own experiences or perceptions. Whereas most academic writing tasks require main points to be supported with references to the literature or to current practice, teachers' reflective writing involved recording their personal views, impressions or observations. However, it was more than simply a description of their observations or thoughts. Teachers' reflective writing involved evaluating their experiences, and thinking about both the strengths and limitations of their classroom practice.

\section{Research Question}

What do teachers do in the classroom to ensure effective learning and teaching?

\section{Methodology}

Qualitative methods were used to collect and analyse data. These teachers had participated in a mathematics and science colloquium attended by 450 teachers. Those attending the colloquium were divided into smaller groups to discuss various topics related to the teaching of mathematics and science. 21 teachers participated in the study. Of these, 15 were female and 8 male teachers. 5 had an honours qualification in mathematics and science education; 1 had an honours qualification in education management; 8 had a diploma in education; and 7had an advanced certificate in education, specialising in mathematics and science. Of the 21 participants, 6 had more than 20 years' experience, 7 had between 11 and 20 years' experience, 5 had between 6 and 10 years' experience, and only 1 had less than 5 years' experience. Only 4 of the participants were teaching higher grades (grades 10-12), while 17 were teaching grades 1 to 3. 
The teachers were given a reflective task. They were given 45 minutes in which to reflect on the following three open-ended questions:"What do you do in the classroom to ensure effective learning and teaching?"; "Describe some areas of the teaching of Maths and Science that could be improved to ensure effective teaching and learning"; and "How can we teach better?". Teachers were asked to write down their responses, and at the end of the 45 minutes allocated, all 21 submitted their written responses.

To elaborate further on the written responses, focus group interviews were conducted with the participants. The interview schedule comprised questions intended to obtain clarity on the written reflections the participants had submitted. The interviews took roughly an hour, and afforded teachers the opportunity to share ideas about classroom practice.

The written responses were collated and inspected in order to identify common themes. The phenomenographic approach was used to categorise and analyse the responses, the intention behind these categories being to capture the qualitative understanding of the phenomenon (classroom practice) (Marton \& Booth, 1997). This approach was chosen because of its usefulness in representing data; the phenomenographic approach makes it possible to view the ideas as constituting an internal relation between the teacher and his or her world (Marton \& Booth, 1997).

The teachers' responses were interpreted for "variation of meanings" and placed into temporary categories referred to as the "pool of meanings" (Marton\& Booth, 1997). Then, through a lengthy process of iteration, the characterisations of the categories as qualitatively distinct methods of classroom practice were identified. Researcher bias in interpretation was minimised by repeating the iterative process of data analysis after a few weeks. Cross checks to improve the methodological credibility of the characterisation of the categories included examining relevant literature.

\section{Discussion of Results}

\subsection{Reflective question: What do you do in the classroom to ensure effective learning and teaching?}

A wide body of research shows that the single most significant factor affecting learner achievement is classroom instruction. In a study, Mortimore and Sammons (1987) found classroom instruction to have more impact on student learning than any other factor. As McKinsey \& Company concluded in their study of the world's best schools, "The only way to improve outcomes is to improve instruction."

It is acknowledged that there are a variety of teaching strategies, but the most crucial factor is how teachers alternate their teaching strategies. This is because the success of teaching depends mainly on the effective use of the available teaching strategies. One of the teachers stated, "I use different strategies/methods of teaching and learning". Teachers may well alternate teaching strategies to capture the interest of learners. A variety of teaching strategies used in the classroom was identified, one of which was play, which teachers reported using to enhance learning. Play as a teaching strategy may have both advantages and disadvantages. An advantage is that many of the learners in primary and high school are at a stage where play forms part of their daily activities, and it is something they find enjoyable. However, play can be less successful as a strategy if a teacher has not planned his or her lesson properly, or if the play is not controlled. It should be clear how play will benefit learning in terms of its purpose and execution in the classroom.

Some teachers reported using practical work as a teaching strategy. This requires suitable equipment, as without it, practical work can be unsuccessful; learning science in particular requires that learners touch and see during experiments. However, teachers can improvise by using existing materials for practical work. The use of practical work in teaching requires real, practical examples so that learners can see the real-life relevance of the practical work.

Teachers explained that they encouraged learners to participate actively in the classroom by creating interest in the subject. Teachers can do a variety of things to capture learners' interest. One of the teachers explained: "When I introduce the topic, I make sure that my introduction is clear and understandable and always try to relate it with things that they familiar with, (everyday life experience)."This teacher believed in proper lesson planning, with the main focus being on capturing the learner's interest from the beginning of the lesson. Another teacher emphasised: "I present the subject in a well organised manner."

Planning a lesson is critical, because when a lesson is well planned, the teacher knows what to teach, how to teach it, and when to teach it. This means ensuring that the introduction is clear and understandable, and that learners understand the relationship between what they are going to learn and everyday experience.

As part of the lesson planning, some teachers suggested group discussions. Many things can happen during group discussions. For instance, learners can discuss what they already know (pre-knowledge) about the topic to be taught, and they can be given a problem to solve. However, every learner should participate actively so that he or she 
realises the benefits of a group discussion. In this context, teachers can try to encourage underperforming learners. One of the teachers explained:"I try and help underperforming learners by giving them individual attention":this prevents learners who do not understand from being left unattended, as they may then lose interest in the subject. Learners are given an opportunity to participate actively in the discussions by being allowed to comment, ask questions and help each other with regard to topics of interest.

Teachers reported making every effort to treat all learners equally, and encouraging learners to take responsibility for their own learning. A teacher stated, "I motivate learners to ask questions when they do not understand."This shows how important it is for teachers to be approachable, so that learners feel comfortable asking questions. In addition, the classroom atmosphere should be supportive, so that learners are not afraid to ask questions, and do not fear that they will be laughed at. Teachers should therefore find ways to create a classroom environment that is conducive to effective learning and teaching.

Learners are given homework as a way of keeping them engaged. Learners should be encouraged to do their homework, and to do it at home. A way to encourage them is to let them present their work to their peers, and teachers can praise them for good performance. Homework should be interesting, and learners should not perceive it as a punishment. The aim should be for learners to be motivated to come to class the following day.

Learner motivation has been identified as instrumental in influencing the engagement of learners in the learning process. An important aim of science education is to empower learners by nurturing the belief that they have the capacity to succeed in science learning and to cultivate the adaptive learning strategies required to help to bring about that success. Research shows that poor performance in school science is attributable mainly to the inability of science curricula and classroom practices to ignite the interest of learners in learning science (Velayutham, Aldridge \& Fraser 2011). Learner's self-regulation in academic settings has been identified as a pivotal construct that influences learner engagement in learning (Boekaerts \& Cascallar, 2006).

\subsection{Reflective question: Describe some areas of the teaching of Maths and Science that could be improved to ensure effective teaching and learning?}

\subsubsection{Improving teachers' and learners' skills in geometry}

Teachers suggested that in-service training in specific content areas would be helpful. The majority identified finance and geometry as areas in which they would like training. A teacher stated: "Geometry could be improved if learners can be provided with mathematical instruments for construction, "which suggests that a lack of appropriate resources is hampering learner performance.

\subsubsection{Improving learners' counting skills}

Many teachers observed that learners had problems counting. However, this was not surprising, as this phenomenon had already been revealed in the Annual national Assessment (ANA) results. The ANA results indicate that learners do not have counting skills. The fact that teachers are doing something to help learners overcome the difficulties they experience with counting is encouraging. A teacher reported: "I start my lesson everyday by letting learners count forward and backward."Some learners may interpret this as a way of making fun of them, but they will later come to realise the purpose of the activity. An activity such as this can help improve the learners' concentration skills ahead of a lesson. Some teachers use this type of activity as an ice breaker. The most important thing, however, is its value in improving learners' counting skills.

\subsection{Reflective question: What can we do better?}

\subsubsection{Improving the learning environment}

Teachers emphasised the role of a supportive learning environment in enhancing the teaching and learning of mathematics in the classroom. A number of factors can improve the learning environment of learners in schools, including intrinsic and extrinsic motivation of learners.

Ryan and Deci (2002) describe motivation as a process in which a person's way of thinking has an important role. These authors suggest that two primary cognitive processes affect motivation, namely a change in the perceived locus of 
causality and a change in perceived competence. When the perceived locus of causality changes to a more internally perceived locus, the intrinsic motivation or the more self-determined forms of extrinsic motivation will be enhanced. When learners are extrinsically motivated, they perceive the locus of causality and the regulation of their studying activities to be external to themselves, whereas when students are intrinsically motivated, they perceive the locus to be within themselves. Change in perceived competence is related to the psychological need for competence. Events that increase perceived competence enhance intrinsic motivation, whereas events that reduce perceived competence tend to undermine intrinsic motivation.

Ryan and Deci (2002) define intrinsic motivation as an "inherent tendency to seek out novelty, and challenges, to extend and exercise one's capacities, to explore and to learn." Intrinsically motivated behaviour is characterised by concentration and engagement; it occurs spontaneously, and people become wholly absorbed in it. Intrinsically motivated activity gives rise to interest, excitement, and enjoyment. Intrinsically motivated behaviours are based on the need to feel competent and self-determined. Teachers who support autonomy have been shown to have more intrinsically motivated students with higher levels of self-esteem compared with the students of teachers who are control oriented (Deci, Nezlek \& Sheinman, 1981).

Providing choice rather than control and acknowledging students' inner experiences therefore enhances intrinsic motivation, and student learning improves (Deci\& Ryan, 2000). Vallerand, Pelletier, Blais, Briere, Senecal, and Vallieres (1992) have divided intrinsic motivation (IM) into three types: IM to know, IM to accomplish things, and IM to experience stimulation. Several studies (cfDeci, 1975; Deci\& Ryan, 1985) have shown that intrinsic motivation has a number of positive effects on learning. However, it is unrealistic to imagine that all science learning can be intrinsically motivated. That is, it is not possible to make all the goals of the curriculum intrinsically motivating, and in a classroom situation it is not always possible to give students choices in terms of what they are to learn (see Byman \& Kansanen, 2008). Initially, intrinsic and extrinsic motivation were described as dichotomous, and extrinsic motivation was even said to be damaging to intrinsic motivation (Deci, 1975). However, Deci and Ryan (1985) subsequently refuted the notion that intrinsic and extrinsic motivation were mutually exclusive.

Teachers' efforts are intended to motivate learners extrinsically. This is because, through an internalisation process, extrinsically motivated behaviours can become increasingly self-determined or autonomous (Byman, Lavonen, Juuti \& Meisalo, 2012). When the internalisation process succeeds, learners will acknowledge the importance of the aims of the curriculum, and will assimilate these into their integrated sense of self, and thus fully accept them as their own. Similarly, self-determination theory draws distinctions between four types of extrinsic motivation based on the degree of self-determination, namely external, introjected, identified, and integrated regulation. External and introjected regulation are considered to be relatively controlled forms of extrinsic motivation, whereas identified and integrated regulation are considered to be relatively autonomous. External regulation refers to intentional behaviours engaged in to earn some expected reward or to avoid a threatened punishment. Externally regulated behaviours are the least self-determined behaviours because the underlying values have not been internalised. A learner who does his or her homework to avoid parental reproach is externally regulated. Working only if the teacher is in the vicinity is a further example. Externally regulated studying tends to be characterised by poor maintenance and transfer once the teacher's control is withdrawn.

\subsubsection{Stakeholder support}

The issue of stakeholder support is becoming part of the schooling system to an increasing degree. This is because schools cannot operate solely on their own. They need the constant support of all levels of the education system, including circuit, district, provincial and national departmental levels. Teachers feel the need for support in order to optimise their performance at school level. Regular visits to offer the necessary support to schools are encouraged.

\section{Conclusion}

The major contribution of the study reported on here lies in the documentation of practical initiatives employed by teachers to motivate learners in the classroom. Much can be learnt from teachers' reflection on their classroom practices. Among the most important were the initiatives that teachers mentioned implementing to make the classroom experience more enjoyable to the learners. The exercise they engaged in gave them the opportunity to take stock of their actions and suggest ways to improve the teaching and learning of mathematics and science. Key in their reflection was their efforts to instil learner interest in the subject and encourage classroom participation. Their initiatives focused on the use of different teaching strategies to capture the interest of learners. Teachers mentioned four significant obstacles, namely 
learners' inability to count; the inadequacy of teachers' geometry teaching skills; the environment in which learners learn; and the lack of stakeholder support(departmental officials in particular were mentioned). These four obstacles should receive particular attention. In addition, teachers were shown to require training in specific content areas, such as geometry.

\section{References}

Boekaerts, M., \& Cascallar, E. (2006). How far have we moved toward the integration of theory and practice in self-regulation? Educational Psychology Review, 18, 199-210.

Boud, D., \& Walker, D. (1998). Promoting reflection in professional courses: the challenges of context. Studies in Higher Education, 23(2),191-206.

Bolman, L. G., \& Deal, T. E. (1991). Reframing organizations. San Francisco: Jossey-Bass.

Byman, R., Lavonen, J., Juuti, K., \& Meisalo, V. (2012). Motivational orientations in physics learning: a self determination theory approach. Journal of Baltic Science Education, 11(4).

Byman R., Kansanen, P. (2008). Pedagogical thinking in a student's mind: A conceptual clarification on the basis of self-determination and volition theories, Scandinavian Journal of Educational Research, 52 (6), pp.603-621.

Deci, E.L. (1975). Intrinsic motivation. New York: Plenum Press.

Deci, E.L., \& Ryan, R.M. (1985). Intrinsic motivation and self-determination in human behavior.New York: Plenum Press.

Deci, E.L., \& Ryan, R.M. (2000). The "what" and "why" of goal pursuits: human needs and self-determination of behavior. Psychological Inquiry, 11,227-268.

Deci, E.L., Nezlek, J., \& Sheinman, L. (1981).Characteristics of the rewarder and intrinsic motivation of the rewardee.Journal of Personality and Social Psychology, 40,1-10.

Dewey, J. (1933). How we think. Boston, MA: DC Heath and Co.

Marton, F., \& Booth, S. (1997). Learning and awareness. New Jersey: Lawrence Erlbaum Associates.

McKinsley \& Company. (2007). How the world's best-performing school systems come out on top.

Moon, J. (1999).Reflection in learning and professional development. London: Kogan Page.

Mortimore, P., \& Sammons, P. (1987). New evidence on effective elementary schools. Educational Leadership, 45 (1), 4-8.

Osterman, K.F., \& Kottkamp, R.B. (1993). Reflective practice for educators:improving schoolingthrough professionaldevelopment. Newbury Park, CA: Corwin Press.

Ryan, R.M., \& Deci, E.L. (2002). An overview of self-determination theory: an organismic-dialectical perspective. In EL Deci \& RM Ryan (Eds.), Handbook of self-determination research (pp. 3-33). Rochester, NY: The University of Rochester Press.

Vallerand, R.J., Pelletier, L.G., Blais, M.R., Briere, N.M., Senecal, C \& Vallieres, E.F. (1992). The academic motivation scale: a measure of intrinsic, extrinsic, and amotivation in education. Educational and Psychological Measurement, 52, 1003-1017.

Velayutham, S., Aldridge, J., \& Fraser, B. (2011). Development and validation of an instrument to measure students' motivation and selfregulation in science learning. International Journal of Science Education, 33(15), 2159-2179. 